American Journal of Economics and Business Administration 3 (3): 498-505, 2011

ISSN 1945-5488

(C) 2011 Science Publications

\title{
Accreditation of Emergency Department at a Teaching Hospital in Tehran University of Medical Sciences in 2010
}

\author{
${ }^{1}$ Fereshteh Farzianpour, ${ }^{1}$ Roholah Askari, ${ }^{1}$ Amin Torabipoor Hamedani, \\ ${ }^{2}$ Gholamosien Khorshidi, ${ }^{3}$ Sanaz Amirifar and ${ }^{4}$ Shadi Hosseini \\ ${ }^{1}$ Department of Health Management and Economics, \\ School Public Health Tehran, University of Medical Sciences, Tehran, Iran \\ ${ }^{2}$ Department of Management of Business, \\ Faculty of Management and Accounting, Shahid Behashti University, Tehran, Iran \\ ${ }^{3}$ Department of Health Services Administration, \\ Tehran University of Medical Sciences, Tehran, Iran \\ ${ }^{4}$ Department of Management, Tehran University, International Campous, Kish Island, Iran
}

\begin{abstract}
Problem statement: Considering the importance of emergency departments in healthcare system and the high mortality rate of patients referred to these departments, it is crucial to provide quality services in emergency departments. Accreditation is a systematic process for improving quality of care and it enables managers to assess and evaluate the healthcare system. Accreditation of an organization provides an obvious commitment for improving quality of safety, quality of patient care, ensuring safety surveillance and continuous activities for reducing dangers which threaten patients and staff. Therefore, given the vital role as well as and the perpetual and indispensable service provided by the emergency departments, it is necessary to re-evaluate the manner of service provision in these departments according to the standards and criteria of accreditation, so that an observance of these criteria will lead to improvement of emergency medicine in Iran. Thus, the present study was undertaken with the purpose of accreditation of emergency department of a teaching hospital of Tehran University of Medical Sciences according to the standards of Iranian Deputy of Health and the JCI. Approach: This is a descriptive-analytic study with a cross-sectional structure. Our study population consisted of 50 individuals of the healthcare staff (physicians and nurses) working in morning and evening work shifts of the emergency department in the teaching hospital. Data collection tools consisted of standard questionnaires of the Deputy of Health (9 series) and questionnaires developed by authors based on the standards of the Joint Commission International (JCI) regarding patient satisfaction with services provided in emergency departments. In order to determine the reliability and validity of the data collection tools, professors and experts reviewed the questionnaire of quality and patient safety in accordance with standards of quality patient safety from the standards of patient satisfaction prepared by the JCI. Subsequently, the questionnaires were used in the emergency department of a teaching Hospital with approval of the head of department. Moreover, they said questionnaire was critiqued for its content and then reviewed conceptually. The reliability of the questionnaire was confirmed with a Cronbach's $\alpha$ of 95\%. Results: According to the relevant standards and the checklists provided by the Deputy of Health for influencing factors (such as human resources, ethical issues and observance of religious measures, structural issues, medical equipment and medications, provision of other medical services, nonmedical equipment), our evaluation of the emergency department in teaching Hospital yielded a score of 1626 points ( $86.81 \%$ of the maximum score) for the department. Conclusion: The above findings the emergency department in this hospital requires certain plans for improving the status quo. Therefore, the current deficiencies must be addressed with a comprehensive plan so that accreditation by the JCI may become feasible.
\end{abstract}

Key words: Emergency medicine, teaching hospital, Joint Commission International (JCI), healthcare services, influencing factors, hospital yielded, religious measures, nonmedical equipment

Corresponding Author: Fereshteh Farzianpour, Department of Health Management and Economics, School Public Health, Tehran University of Medical Sciences, Tehran, Iran 


\section{INTRODUCTION}

Regardless of vastness and affluence, social health and the manner of providing healthcare services constitute an essential issue in most countries of the world (Kallstroma, 2010). Many developing countries are endeavoring towards a healthcare system for meeting the basic needs of their societies (Carpenter et al., 2010). Such countries need to plan meticulously in order to ensure the optimal use of their scarce resources (WHO, 2010). Even in many developed countries, the growing economic pressures are threatening the healthcare system which has been in place since long ago (JCI, 2011). It must now be determined which services must be provided and which ones are dispensable. All healthcare centers and the Joint Commission International (JCI) have proposed standards for improvement of health services and accreditation regardless of the country in question (JCI, 2011).

Accreditation is a monitoring system for acceptability of standards and it entails procedures for periodic and confidential evaluation of an organization's resources. It also seeks to attain reliability for the services provided according to the previously implemented standards (JCR, 2005).

Accreditation is a systematic process for improving the quality of care and it may assess the healthcare system. Accreditation of an organization provides an obvious commitment for improving quality of safety, quality of patient care, ensuring safety surveillance and continuous activities for reducing dangers which threaten patients and staff (Paradise, 2004; Perina et al., 2011). It is considered a qualitative evaluation and en efficient managerial tool, thus attracting the attention of organizations worldwide (JCI, 2002).

The Joint Commission International (JCI) is a branch of the joint commission with the mission of improving the quality of healthcare internationally (Harrington, 2007).

The joint commission and its predecessor (in the United States) have a history of 75 years of devoting themselves to improving the quality and safety of healthcare services (JCI, 2011). Today, the joint commission is the largest source accrediting healthcare organizations in the United States (Pronovost et al., 2006).

Through voluntary accreditation, JCI supervises the programs of some 16 thousand healthcare centers. JCI is a non-governmental and non-profit institute (Jack et al., 2009).

JCI accreditation is a collection of diverse innovations planned for a standardized system of healthcare evaluation as a response to the growing requests worldwide. The aim is to provide an objective standard-based procedure for evaluating healthcare organizations throughout the world. The accreditation program is based on international standards which are compatible with local needs (Atkinson et al., 2009).

A universal and thorough improvement of quality will reduce risks for patients and staff. Such risks may be abundant in clinical procedures and physical environments (Cohen et al., 2010).

Quality and safety stem from the daily activities of healthcare professionals and other staff. As long as physicians and nurses make efforts to evaluate patients' needs and provide care, they will be able to improve truly in terms of helping their patients and reducing the risks. Similarly, managers, supporting staff and others may implement these standards to realize the efficiency of procedures, wiser use of resources and reduction of physical risks (Smith, 2010).

This approach holds that most managerial and clinical quality issues are interrelated; therefore, any attempt aimed at improving these procedures must be conducted in a universal frame of quality management and supervised by a committee or delegate responsible for quality and patient safety (Farzianpour et al., 2009; 2010; 2011).

The international accreditation standards cover the entire spectrum of managerial and clinical activities in a healthcare organization and shape a framework for improving these activities, as well as reducing risks caused by fluctuations in processes (Farzianpour et al., 2009; 2010; 2011).

Therefore, the framework provided by these standards is applicable to a wide range of structural programs and unofficial approaches of quality and patient safety. This framework may be integrated into traditional monitoring programs such as those dealing with natural disasters (danger management) and resources use (Farzianpour et al., 2009; 2010; 2011).

In the Iranian healthcare system, hospitals and particularly emergency departments have always been the basis of popular judgment on the function of the ministry of health, due to the high load of patients and the direct impact of emergency departments on the prognosis of clinical procedures.

Emergency departments play a crucial role in ensuring people's health and saving lives in disasters and accidents (Farzianpour et al., 2009; 2010; 2011). Due to the vital role and the perpetual need for their services, they must be provided with necessary equipment and medications under any circumstance (Farzianpour et al., 2009; 2010; 2011; Improving America's Hospitals, 2010). Regulations have been prepared based on the minimum requirements of emergency departments in order to protect people's health and recovery of victims of accidents and medical emergencies. These regulations are in line with the 
objectives and responsibilities of the ministry of health and medical education, as determined by the scopes of the Islamic Republic of Iran. They are legally obliging in all healthcare centers including those affiliated with the ministry of health and medical education, other governmental organizations, the private sector, charity organizations and any other organizations which assume healthcare responsibilities and incompliance with these regulations is considered a felony and prosecutable under law. In this document, all standards regarding medical emergencies have been marked with the letter "S", indicating an obliging regulation for emergency medicine and departments (Farzianpour, 2011).

In Iran, accrediting systems and hospitals have been mostly preoccupied with the physical space, buildings and equipment of hospitals. Novel accrediting systems, however, concentrate on a comprehensive monitoring of services and people's satisfaction (Farzianpour et al., 2009; 2010; 2011).

For the purpose of evaluation, modern hospitals consider issues such as manner of reception, admitting patients in clinics, admitting patients in wards, educating patients and their companions, number of medicines available in the hospital, not referring patients to their companions for obtaining medicines and not referring patients or their companions outside the hospital for obtaining medicines (Farzianpour et al., 2010).

Currently, governmental hospitals are accredited through medical universities which conduct evaluation and accreditation (Farzianpour et al., 2010).

Therefore, given the vital role of emergency medicine as well as the perpetual need for its services, it is essential to conduct accreditation to evaluate the level of observing standards and regulation; this process will lead to identification of improvable issues, thus enhancing emergency medicine (Farzianpour et al., 2010).

The present study was conducted in order to accredit the emergency department in a teaching Hospital of the Tehran University of Medical Sciences according to standards of the Deputy of Health and the JCI (Farzianpour et al., 2010).

\section{MATERIALS AND METHODS}

This is a practical descriptive-analytic study started in September 2009 and finishing in July 2010. Our population study consisted of 50 personnel (physicians and nurses) employed in morning and evening work shifts of the emergency department in a teaching Hospital.

In this study, we used checklists prepared for evaluation of emergency medicine, comprising 9 checklists as follows: (1) Human force, (2) Ethical and religious issues, (3) Structural issues, (4) Medical equipment and medications, (5) Nonmedical and safety equipment, (7) Provision of other medical services, (8)Average time of first visit by a physician and the average time of first service provided by a nurse, (9) Patients' satisfaction with the department.

Each series consisted of relevant questions with a certain range of scores. We evaluated the emergency department of this teaching hospital using these standards and through interviews with qualified individuals.

For accreditation of patient-oriented sections of the emergency department the Hospital, we used questionnaires of quality and patient safety (QPS*1) prepared by the JCI, with a total of 37 statements. These questionnaires, which form our hypotheses as well, consist of 5 parts, as follows: (1) Standards of leadership and planning, (2) Standards of designing clinical and managerial procedures, (3) Standards of data collection for quality monitoring and (5) Standards of enhancement.

Each part contains several questions; respondents select one of three choices to answer the questions, indicating that the standard in question is observed, is not observed or is relatively observed in the emergency department.

Once the questionnaires were completed, data were analyzed using appropriate statistical tests such as chi-square (with a confidence interval of 95\%) on SPSS software and the results were presented in diagrams and descriptive and analytic statistics.

In order to determine the reliability and validity of the data collection tools, professors and experts reviewed the questionnaire of quality and patient safety in accordance with standards of quality patient safety from the standards of patient satisfaction prepared by the JCI. Moreover, they said questionnaire was critiqued for its content and then reviewed conceptually. The reliability of the questionnaire was confirmed with a Cronbach's $\alpha$ of $95 \%$.

It must be noted that the checklists pertaining to qualitative evaluation of emergency departments have been confirmed by the Deputy of Health at the Ministry of Health and Medical Education in Iran.

We complied with the ethical considerations throughout the present study, such as acquisition of permit from the school of medicine to be presented to the hospital and the deputy of health, voluntary and deliberate participation of study units.

\section{RESULTS}

According to the relevant standards and the checklists provided by the Deputy of Health for influencing factors (such as human resources, ethical issues and observance of religious measures, structural 
issues, medical equipment and medications, provision of other medical services, nonmedical equipment), our evaluation of the emergency department in the Hospital yielded a score of 1626 points $(86.81 \%$ of the maximum score) for the department.

Results of QPS analysis: We used the standards of Quality and Patient Safety (QPS) prepared by the JCI in order to assess patients' satisfaction. The findings, for each domain of QPS standards, are as follows. It is noteworthy that we used chi-square test to analyze each domain of QPS standards and the findings are expressed as observed and expected frequencies (Table 1).

Level of compliance (implementation) of QPS standards in the domain of leadership and planning in hospital: Considering the value of chi-square $\left(\chi^{2}=22.36\right)$, which is larger than the error level of $5 \%$ with a degree of freedom of 2 , the $\mathrm{H}_{0}$ hypothesis (i.e., lack of difference between the observed frequencies) is rejected; in other words, the differences between observed frequencies are real and it may be stated with $95 \%$ of confidence that $38 \%$ of individuals believed that the standards of leadership and planning are implemented in the hospital, $58 \%$ believed that these standards are relatively implemented in the hospital and only $4 \%$ were of the opinion that the standards are never implemented in the hospital (Table 1 and 2).
Level of compliance (implementation) of QPS standards in the domain of managerial and clinical standards: Considering the value of chi-square $\left(\chi^{2}=12.28\right)$, which is larger than the error level of $5 \%$ with a degree of freedom of 2 , the $\mathrm{H}_{0}$ hypothesis (i.e., lack of difference between the observed frequencies) is rejected; in other words, the differences between observed frequencies are real and it may be stated with $95 \%$ of confidence that $44 \%$ of individuals believed that the managerial and clinical standards are implemented in the hospital, $46 \%$ believed that these standards are relatively implemented in the hospital and only $10 \%$ were of the opinion that the standards are never implemented in the hospital (Table 1 and 2).

Level of compliance (implementation) of QPS standards in the domain of quality monitoring in hospital: Considering the value of chi-square $\left(\chi^{2}=\right.$ 22.36), which is larger than the error level of $5 \%$ with a degree of freedom of 2 , the $\mathrm{H}_{0}$ hypothesis (i.e., lack of difference between the observed frequencies) is rejected; in other words, the differences between observed frequencies are real and it may be stated with $95 \%$ of confidence that $38 \%$ of individuals believed that the standards of data collection for quality monitoring are implemented in the hospital, 58\% believed that these standards are relatively implemented in the hospital and only $4 \%$ were of the opinion that the standards are never implemented in the hospital (Table 1 and 2).

Table 1: Compliance with the five domains of QPS standards in emergency department of the hospital in study/2010

\begin{tabular}{|c|c|c|c|c|c|c|c|}
\hline Domains & Compliance & Frequency $(\mathrm{N})$ & Percent & Observed values & Expected values & Remaining values & Test result P-value \\
\hline Leadership & Completely & 19.0 & 38 & 19 & 16.7 & 2.3 & \multirow{4}{*}{0.001} \\
\hline \multirow{3}{*}{ and Planning } & Relatively & 29.0 & 58 & 29 & 16.7 & 12.3 & \\
\hline & Never & 2.0 & 4 & 2 & 16.7 & -14.7 & \\
\hline & Total & 50.0 & 100 & 50 & 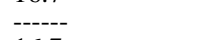 & & \\
\hline Managerial and & Completely & 22.0 & 44 & 22 & 16.7 & 5.3 & \multirow[t]{3}{*}{0.002} \\
\hline \multirow{2}{*}{ Clinical Standards } & Relatively & 23.0 & 46 & 23 & 16.7 & 6.3 & \\
\hline & Never & 5.0 & 10 & 5 & 16.7 & -11.7 & \\
\hline \multirow[t]{5}{*}{ Quality Monitoring } & Completely & 50.0 & 100 & 50 & & & \\
\hline & Total & 29.0 & 58 & 29 & 16.7 & 12.3 & \multirow[t]{4}{*}{0.001} \\
\hline & Relatively & 19.0 & 38 & 19 & 16.7 & 2.3 & \\
\hline & Never & 20.0 & 4 & 2 & 16.7 & -14.7 & \\
\hline & Total & 50.0 & 100 & 50 & & & \\
\hline Analysis of & completely & 24.0 & 48 & 24 & 16.7 & 7.3 & \multirow[t]{2}{*}{0.001} \\
\hline \multirow[t]{6}{*}{ Monitoring Data } & Relatively & 23.0 & 46 & 23 & 16.7 & 6.3 & \\
\hline & Never & 30.0 & 6 & 3 & 16.7 & -13.7 & \multirow{5}{*}{0.001} \\
\hline & Total & 50.0 & 100 & 50 & ------ & 2.3 & \\
\hline & Relatively & 30.0 & 60 & 30 & 16.7 & 13.3 & \\
\hline & Never & 10.0 & 2 & 1 & 16.7 & -15.7 & \\
\hline & Total & 50.0 & 100 & 50 & ------- & ---------- & \\
\hline
\end{tabular}

Table 2: Assessment of compliance with the five domains of QPS standards in emergency department of the hospital in study/2010

\begin{tabular}{|c|c|c|c|c|c|}
\hline \multirow[b]{2}{*}{ Domains } & & \multicolumn{3}{|l|}{ Total QPS } & \multirow[b]{2}{*}{ Total } \\
\hline & & Implemented & relatively implemented & Not implemented & \\
\hline Leadership and planning & Count (\% within total group) & $72(24.00 \%)$ & $138(46.00 \%)$ & $90(30.00 \%)$ & $300(100.00 \%)$ \\
\hline Managerial and clinical standards & Count ( $\%$ within total group) & $27(27.00 \%)$ & $46(46.00 \%)$ & $27(27.00 \%)$ & $100(100.00 \%)$ \\
\hline Quality monitoring & Count (\% within total group) & $377(35.90 \%)$ & $440(41.90 \%)$ & $233(22.20 \%)$ & $1050(100.00 \%)$ \\
\hline Analysis of monitoring data & Count ( $\%$ within total group) & $81(27.00 \%)$ & $155(51.70 \%)$ & $64(21.30 \%)$ & $300(100.00 \%)$ \\
\hline Enhancement & Count (\% within total group) & $44(29.30 \%)$ & $74(49.30 \%)$ & $32(21.30 \%)$ & $150(100.00 \%)$ \\
\hline Total & Count ( $\%$ within total group) & $601(31.60 \%)$ & $853(44.90 \%)$ & $446(23.50 \%)$ & $1900(100.00 \%)$ \\
\hline
\end{tabular}


Level of compliance (implementation) of QPS standards in the domain of analysis of monitoring data: Considering the value of chi-square $\left(\chi^{2}=16.84\right)$, which is larger than the error level of 5\% with a degree of freedom of 2, the $\mathrm{H}_{0}$ hypothesis (i.e., lack of difference between the observed frequencies) is rejected; in other words, the differences between observed frequencies are real and it may be stated with 95\% of confidence that $48 \%$ of individuals believed that the standards of analysis of monitoring data are implemented in the hospital, $46 \%$ believed that these standards are relatively implemented in the hospital and only $6 \%$ were of the opinion that the standards are never implemented in the hospital (Table 1 and 2).

Level of compliance (implementation) of QPS standards in the domain of enhancement: Considering the value of chi-square $\left(\chi^{2}=25.72\right)$, which is larger than the error level of 5\% with a degree of freedom of 2, the $\mathrm{H}_{0}$ hypothesis (i.e., lack of difference between the observed frequencies) is rejected; in other words, the differences between observed frequencies are real and it may be stated with $95 \%$ of confidence that 38\% of individuals believed that the standards of enhancement are implemented in the hospital, $60 \%$ believed that these standards are relatively implemented in the hospital and only $2 \%$ were of the opinion that the standards are never implemented in the hospital (Table 1 and 2).

\section{DISCUSSION}

The current standards depict the level of care required for patients or approaches defined by specialist individuals or societies. For each situation, there is a primary standard which represents the minimum required level of quality (JCI, 2011). Provided that these primary standards are observed, the subsequent standards will be considered (ARIAH, 2011). Since a hospital cannot be conceived of as separate services, it is necessary that all sections of a hospital should meet the minimum standards as the first step towards accreditation.

The following will explain the results of evaluation of the emergency department in the hospital:

- The level of acceptability and compliance with the standards of human force in the emergency department of our study is $86 \%$ according to the checklists prepared by the deputy of health. The weakness in this domain pertains to the subset of human force in employment of best nurses for the emergency department with $62.5 \%$, manner of definite presence and activity of nursing staff in the emergency department with 90\%, nurses' familiarity with and observance of scientific basics of nursing with $77.7 \%$, appropriate treatment of patients and their companions by the staff with $75 \%$ and observance of security and safety principles by the staff with $87.5 \%$

- The level of acceptability and compliance with the standards of ethical and religious issues in the emergency department of our study is $95 \%$ according to the checklists prepared by the deputy of health. The weakness in this domain pertains to hygiene and sanitation of public spaces in the emergency department and its surroundings with $91.5 \%$, initial behavior towards patients and others who refer to the department with $91.5 \%$, hygiene and sanitation of diagnostic, therapeutic and auxiliary spaces in the emergency department with $83.3 \%$ and observance of Islamic rules of ethics by the personnel and staff under all circumstances with $91.6 \%$

- The level of acceptability and compliance with the standards of structural issues in the emergency department of our study is $84 \%$ according to the checklists prepared by the deputy of health. The weakness in this domain pertains to access to the emergency department from outside the hospital with $75 \%$, quality and quantity of transportation vehicles in terms of meeting the requirements of the emergency department with $78.5 \%$, quality of transportation vehicles in terms of equipment required for emergency transportation with $91.6 \%$, proper disposition of security and orderly personnel with $83.3 \%$, location of emergency laboratory related to the public hall of the emergency department with $77.7 \%$, location of emergency radiology related to the public hall of the emergency department with $77.7 \%$, physical connection of the emergency department to other wards in the hospital with $55.5 \%$, maps and guiding signs with $50 \%$, security facilities of the emergency department for fire alarm and prevention with $54.5 \%$, security facilities of the emergency department for prevention of electrocution in all places with $44.4 \%$ and observance of safety principles in design and structure of the emergency department with $76.9 \%$.

- The level of acceptability and compliance with the standards of medical equipment and medications in the emergency department of our study is $78 \%$ according to the checklists prepared by the deputy of health. The weakness in this domain pertains to compatibility of clinical spaces with $83.5 \%$, emergency operation room for minor surgeries and its equipment with $91 \%$, isolated clinical spaces for infectious cases with $87.5 \%$, clinical spaces specified 
for follow up and observation with $91 \%$, readily accessible public telephone with $77 \%$, working wheelchairs: Numbers, quality and easy accessibility for everyone under all circumstances with $77.5 \%$, stretchers, standard incubators for critical neonates and infants with $0 \%$, beds compatible for children particularly in terms of side bars with $0 \%$, fixed and mobile lights for each bed with $0 \%$ and beds compatible for emergency conditions (sturdiness, hygiene, protection) with $45.5 \%$

- The level of acceptability and compliance with the standards of nonclinical equipment in the emergency department of our study is $94 \%$ according to the checklists prepared by the deputy of health. The weakness in this domain pertains to appropriate desk and chair for physicians, nurses, patients and companions with $66.5 \%$, appropriate shoes for patients and personnel- special towels for patients with $50 \%$, patients' beds attached to the posterior aspect of emergency trolley with $0 \%$, full oxygen capsule attached to trolley alongside manometer and other accessories with $50 \%$ and presence of emergency shelves in the appropriate place with continuous accessibility with $71.5 \%$

- The level of acceptability and compliance with the standards of provision of other medical services in the emergency department of our study is $84 \%$ according to the checklists prepared by the deputy of health. The weakness in this domain pertains to facilities for peritoneal dialysis under emergency conditions with $0 \%$, facilities for neonatal blood exchange under emergency conditions with $0 \%$, facilities for psychological emergencies with $0 \%$, accessibility and implementation of the standard protocol for burns with $0 \%$, preparation and experience of the emergency department regarding various cases of poisoning with $37.5 \%$, assignment of educational spaces with necessary facilities and equipment with $72.75 \%$ and existence of on-call system for professors and their presence during evening and night shifts and on holidays with $57.14 \%$

- The level of acceptability and compliance with the standards of the average time of the first clinical visit by a physician in the emergency department of our study is $100 \%$ which indicates an excellent quality

- The level of acceptability and compliance with the standards of the first service provided by a nurse in the emergency department of our study is $79 \%$ according to the checklists prepared by the deputy of health. The weakness in this domain pertains to a stable decrease of the time of the first service provided by a nurse over two consecutive sixmonth intervals with $50 \%$

- The level of acceptability and compliance with the standards of patient satisfaction in the emergency department of our study is $95 \%$ according to the checklists prepared by the deputy of health. The weakness in this domain pertains to a stable increase in level of satisfaction of patients referring to the emergency department over at least one sixmonth interval with $90 \%$

In a study by Farzianpour et al. (2010). Titled "preparation of teaching hospitals of Iran University of Medical Sciences for accreditation by the JCI: a patientoriented approach in 2010", it was concluded that the greatest level of compliance with standards pertained to standards of managing drug prescription and administration (83\%) and anesthesiology and surgery cares $(80.2 \%)$, both occurring in General hospital. The least level of compliance was found in standards of patient rights $(47 \%)$ in teaching hospital for accidents and burns. Moreover, in the present study, the level of compliance was $78 \%$ for standards of quality and safety improvement, $70 \%$ for standards of managerial monitoring, $62 \%$ for standards of clinical monitoring and $78 \%$ for standards of data collection and analysis. In general, General Hospital scored higher $(71.5 \%)$ compared to Rajaee (67\%) and Teaching (62.2\%) hospitals (Farzianpour et al., 2010), while our study indicates that the standards of quality and patient safety are fully respected in $31.6 \%$ of cases, relatively respected in $44.9 \%$ of cases and disrespected in $23.5 \%$ of cases.

Another study by Farzianpour et al. (2010) titled "evaluation of prevention and control of infection programs (PCI) in Mazandaran Hospitals, according to the standards of the ministry of health and international accreditation standards (JCI) in 2009" inspected the hospital and completed the checklists to report the following scores for each domain of standards: Program leadership and organization $82.14 \%$, program focus $67.50 \%$, methods of isolation $50 \%$, protective and hand hygiene techniques $90 \%$, program integrity with quality and patient safety improvement $45.83 \%$ and staff education $57.14 \%$ (Farzianpour et al., 2010).

In another study by Farzianpour (2011) the emergency department of Sina Hospital was assessed according to the Baldrige criteria for organizational excellence; out of 1000 possible points, Sina Hospital scored $235.58(23.55 \%)$.

Dia Kamel conducted a study in 2006 to assess the degree of improvement after implementation of JCI standards; it was reported that the hospital's function improved by $49 \%$ after implementation of JCI standards. 
The implementation of standards improved the hospital's function by $32 \%$ from the care providers' point of view, by $10 \%$ from the patients' point of view, by $177 \%$ from the viewpoint of the accreditation committee and by $135 \%$ from the governmental authorities' point of view. 15 months after implementation of standards, the hospital's function regarding patient safety improved by $79 \%$ (Kallstroma, 2010).

Carpenter et al. (2010) reviewed articles regarding indices of patient safety and methods of quantifying the improvement in patient safety in developing countries to conclude that assessments of patient safety are quite limited in these countries and it is essential to develop basic patient safety activities, integrate these activities into the routine services provided as well as patient education about the availability of these activities so that patient safety may be measured and monitored in developing countries (Carpenter et al., 2010).

\section{CONCLUSION}

Therefore, considering the level of compliance with standards and the points acquired in each domain, we recommend the following for improvement of each domain:

- In order to brief the personnel and improve the quality of clinical treatment and considering the high load of activities required in the emergency department, it is recommended to the personnel to attend time management workshops and receive the necessary training

- In accordance with article 7-4 of the standards developed by the Deputy of Health, nurses with further work experience must be employed in emergency departments

- Regarding the facilities of fire alarm in the emergency department, it is recommended to install a central fire alarm system, as well as fire extinguishers (powder and gas) and the fire extinguishing system

- In addition, it is recommended to replace the old ambulances with modern ones which are equipped with modern medical supplies. Also, it is recommendable to increase the number of phone lines and install intercoms between different wards

Considering these findings, it may be concluded that the emergency department of our study requires planning and implementing programs for improving the current status. Thus, a comprehensive program must be designed to address the deficiencies and pave the way towards international JCI accreditation.

In the present study, the authors faced certain limitations such as poor access to the clinical staff due to their heavy work load, unresponsiveness of physicians in certain cases and lack of proper collaboration on the part of the third emergency department in the Hospital.

\section{REFERENCES}

ARIAH, 2011. Improving America's Hospitals - The Joint Commission's Annual Report on Quality and Safety. The Joint Commission. http://www.jointcommission.org/annualreport.aspx

Atkinson, P., A. Chesters and P. Heinz, 2009. Pain management and sedation for children in the emergency department. BMJ., 339: b4234- b4234. DOI: $10.1136 / \mathrm{bmj} . \mathrm{b} 4234$

Carpenter, K.B., M.A. Duevel, P.W. Lee, A.W. Wu and D.W. Bates et al., 2010. Measures of patient safety in developing and emerging countries: A review of the literature. Qual. Safe Health Care, 19: 48-54. DOI: 10.1136/qshc.2008.031088

Cohen, H.S., D.N. Gerding, S. Johnson, C. P. Kelly and G. Vivian et al., 2010. Clinical practice guidelines for clostridium difficile infection in adults: 2010 update by the Society for Healthcare Epidemiology of America (SHEA) and the Infectious Diseases Society of America (IDSA). Infect. Control Hospital Epidemiol., 31: T1-T28. DOI: 10.1086/651706

Farzianpour, F. Emami, AH. Davari-Tanha, F. Hosseini, S. Farzanehnejad, AR., 2010. Educational programs' quality assessment based on graduates' comments. Iranian Red Crescent Med. J., 12: 302-307.

Farzianpour, F., 2011. Program Evaluation of Health Care Management: Is it adjusted for Students Needs? Am. J. Econ. Bus. Admin., 3: 420-424. DOI: 10.3844/ajebasp.2011.420.424

Farzianpour, F., A.H. Emami and M.R. Eshraghian, 2009. The satisfaction of medical practitioners from continuing medical education program of Tehran University of medical sciences. Iranian Red Crescent Med. J., 11: 371-3761.

Farzianpour, F., S. Aghababa, B. Delgoshaei and M. Haghgoo, 2011. Performance evaluation a teaching hospital affiliated to Tehran University of Medical Sciences Based on Baldrige excellence model. Am. J. Econ. Bus. Admin., 3: 277-281. DOI: 10.3844/ajebasp.2011.272.276 
Harrington, N., 2007. JCI Practicum on Quality Improvement and Accreditation. ESQH.

Jack, B.W., V.K. Chetty, D. Anthony, J.L. Greenwald and G.M. Sanchez et al., 2009. A reengineered hospital discharge program to decrease rehospitalization a randomized trial. Ann. Intern. Med., 150: 178-187.

JCI, 2002. Joint Commission International Accreditation Standards for Hospitals. 2nd Edn., Joint Commission Resources, Oakbrook Terrace, IL., ISBN: 0866887792, pp: 190.

JCI, 2011. WHO Collaborating Centre for Patient Safety Solutions.

JCR, 2005. Comprehensive Accreditation Manual for Hospitals: The Official Handbook. 1st Edn., Joint Commission Resources, Oakbrook Terrace, ILL., ISBN: 0866888926.

Kallstroma, M., 2010. Measuring quality performance in healthcare. Total Quality Manage. Bus. Exc., 21: 1058-1058. DOI: 10.1080/14783360903332395
Paradise, A., 2004. Why the Joint Commission on Accreditation of Healthcare Organizations should add new regulations regarding libraries. J. Med. Libr. Assoc., 92: 166-168.

Perina, D.G., R.E. Collier, F.L. Counselman, J.H. Jones and E.A. Witt, 2011. Report of the task force on residency training information (2010-2011), American board of emergency medicine. Annals Emergency Med., 57: 526-534. DOI: 10.1016/j.annemergmed.2011.03.013

Pronovost, P., D. Needham, S. Berenholtz, D. Sinopoli and H. Chu et al., 2006. An intervention to decrease catheter-related bloodstream infections in the ICU. N. Eng. J. Med., 355: 2725-2732. PMID: 17192537

Smith, G., 2010. Medical Electrical Safety Testing Under Attack in the U.S. MAXANT Technologies Inc.

WHO, 2010. Health statistics and health information systems. Service Availability Mapping (SAM). Geneva World Health Organization: pp: 10741079. 